\title{
Transducer for Tension Force Measuring of Strip Materials
}

\author{
Emad Said Addasi \\ Department of Electrical Engineering, Tafila Applied University College \\ Al-Balqa' Applied University, P.O. Box 40, Al-Eys 66141, Tafila, Jordan
}

\begin{abstract}
In winding-up motor drive systems, such as that used in textile industry, it is very important to get a constant tension force for the winding strip material (thread) and to reduce its oscillations. This study recommends a transducer with a special design to be used in the mentioned motor drive systems. By using a piston damper, spring, levers, slider and other simple components the suggested sensor (transducer) can be used to control the motor speed for getting the required thread tension force. Also the suggested transducer avoids the disadvantage of other used conventional transducer: the parasitic (detrimental) oscillations of the thread tension force, which affect the quality of the produced strip material.
\end{abstract}

Key words: Transducer, Electric Drive, Tension Force, Speed Control

\section{INTRODUCTION}

Electric motor drive systems absorb the majority of all produced electrical energy. In the industrial countries, electric motors take about two-third of the entire electrical energy available of which less than $10 \%$ is taken up by dc motors [1-4].

The used motor drive systems in most applications must be designed to satisfy some requirements [5-7] such as: wide speed range, low cost, high efficiency, ease of control and maintenance, small size, bi-directional and others.

But in some cases industry has special requirements. For example in textile industry the winding-up drive for thread production requires a constant tension force of the thread. So the thread tension must be measured continuously by a sensor [8]. And the output signal of this sensor is used to control the motor speed in order to get a constant tension of the winding-up material. The speed of the motor and the tension force of the winding material are measured via rotational transducer [9]. Ben-Brahim et al. [10], Bose and Simoes [11], Peng and Fukao [12] introduced a sensorless control of induction motor speed without rotational transducer.

The used systems do not provide a constant tension force of the winding strip material [6, 13, 14]. This means that the winding drive operates with oscillating tension force. And these oscillations affect the windingup material quality. Solving this problem is recommended by using a special-design transducer. The suggested transducer, at the same time, measures the tension force of the winding material and damps its oscillations.

Suggested Transducer and Motor Drive: Figure 1 and 2 illustrate a general view of the winding motor drive and the main components of the suggested transducer, where: 1- thread; 2- roller; 3- lever; 4,7- stops; 5- return spring; 6- slider (sliding block); 8drum; 9- source of light (LED); 10- shutter (blind); 11tape; 12- spring; 13- fixing stop; 14- nut for spring adjusting; 15,16- light receivers (photodiodes); 17damper; 18- fixed axis for the damper; 19- damper lever; 20- regulator (controller); 21- electrical motor; 22- sensor; 23- coupling joint; 24- thread bobbin.

The suggested system works as follows: In the starting process, which is the most difficult in term of the thread tension force stabilization, the tension and the motor speed are initially zero and the sensor is in its upper position as shown in Fig. 3a. Just after the starting instant the input signal to the controller from the sensor is equal to its maximum value. Hence the lever of the sensor is at its upper position the photodiode 15 is covered and does not receive any light, while the photodiode 16 receives maximum light. In this case the electric motor is working at the maximum feeding voltage. And it begins to rotate to wind the thread around the bobbin. Thus the thread tension increases and, as a result, the lever 3 moves downward.

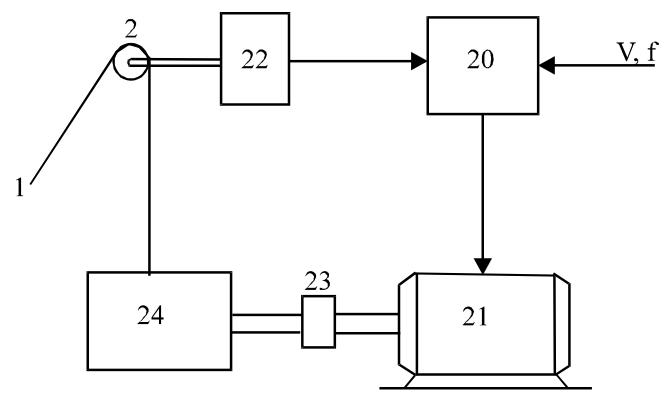

Fig. 1: The General View of the Winding Motor Drive

In winding drives with conventional transducers (without damper) the lever, just after the starting instant, will move abruptly downward to reach its 


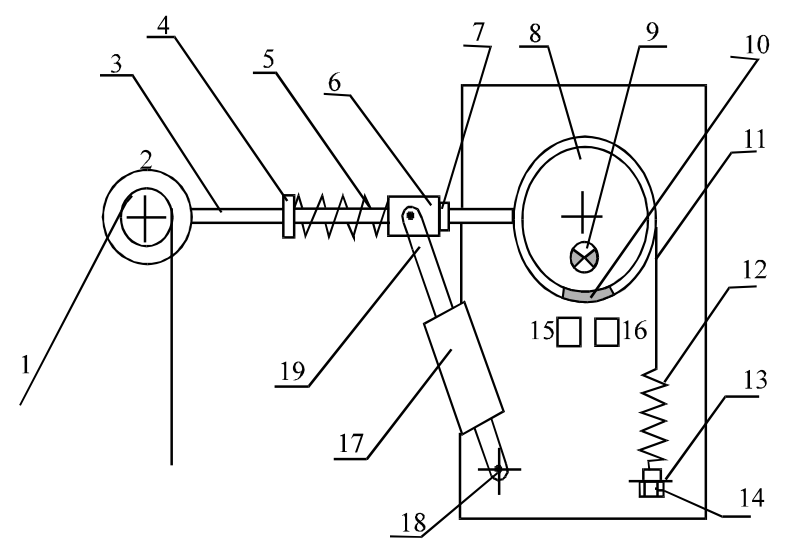

Fig. 2: Sketch of the Suggested Transducer

(a)

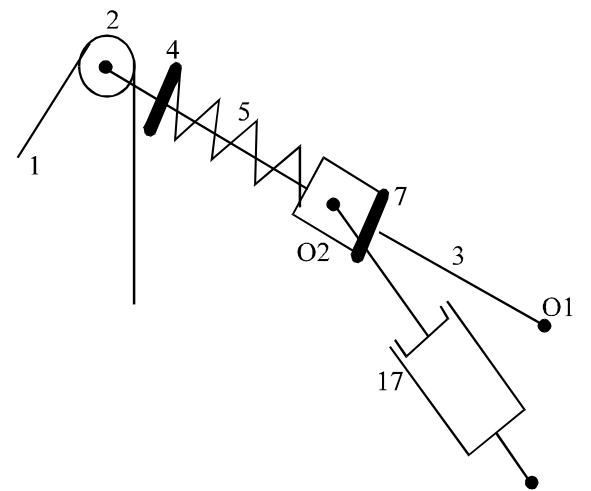

(b)

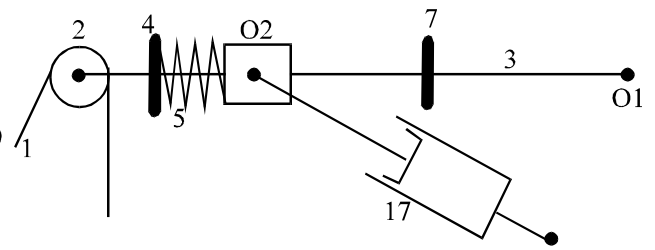

(c)

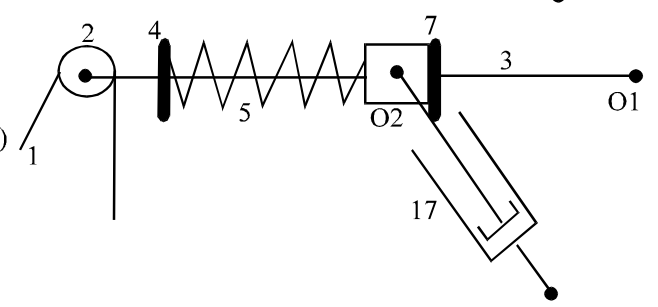

Fig. 3: Different Operating Positions of the Transducer

lowest position and consequently the voltage applied to the motor will be decreased to zero by the controller, which causes the motor to slow dawn. Then the lever moves up and the motor voltage increases, which causes the motor to speed up and so on. So in this case if there is no damper the system will work with oscillations.

But with the suggested damper, after starting the lever first moves quickly downward just to reach the operation position (horizontal) as shown in Fig. $3 \mathrm{~b}$. That is because the damper is not working until this position and the slider 6 slides along the lever 3 to the

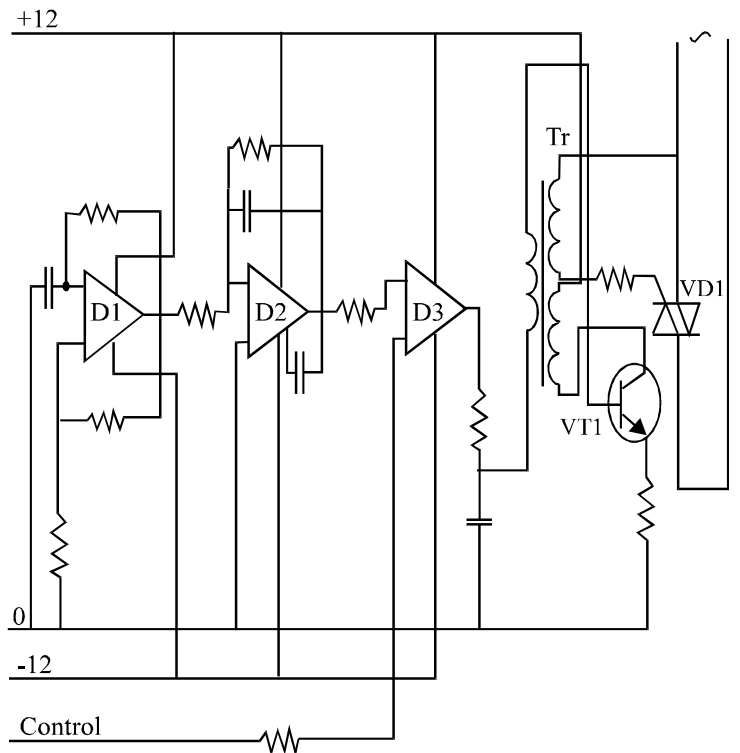

Fig. 4: The Electric Circuit of the Used Regulator

stop 4 that causes the return spring 5 to be compressed (Fig. 3b).

After the spring 5 is compressed the damper begins to operate anti the lever motion more downward. The damper in this case has its maximum effect since the arm $\mathrm{O}_{1} \mathrm{O}_{2}$ is at its maximum value. Therefore, the lever moves smoothly around its horizontal position, while the photodiodes 15 and 16 receive almost the same amount of light and so the motor will operate at the operation voltage without oscillations. Under the act of the compressed spring 5 sliding block 6 moves smoothly and slowly and pushes the damper piston inside the damper. So it moves until it reaches the other stop 7 as it is shown in Fig. 3c.

The used regulator in this system has a rectangular pulse generator (D1), integrator (D2) to get the saw form voltage wave, comparator (D3) and the actuating pulse generator which is composed of transformer $\mathrm{Tr}$, transistor VT1 and triac (VD1) as shown in Fig. 4.

The rectangular pulse generator gives rectangular pulses as shown in Fig. 5a. These pulses are converted to saw-form wave by (D2) as shown in Fig. 5b. This signal is applied to the first input of the comparator, while to the second input is applied a constant voltage (Fig. 5c), which value is proportional to the thread tension force (from the outputs of the photodiodes of the transducer).

At the instant, when the two values of both comparator inputs are equals, comparator abruptly changes its output signal as shown in Fig. 5d. Thus the output signal of this comparator has rectangular form, which duration depends on the thread tension. If this tension decreases low than required, the rectangular pulse duration increases. And if the thread tension increases above the required value the pulse duration decreases. 


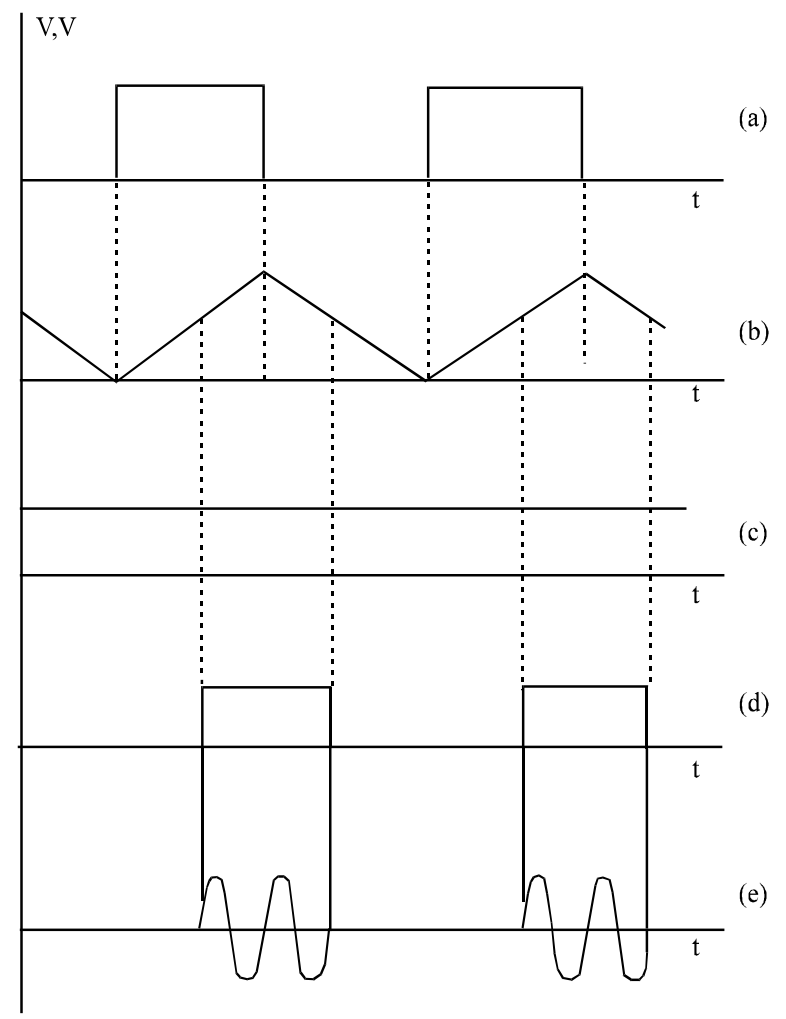

Fig. 5: The Input and Output Signals (Voltages) of the Electric Circuit

Moreover, the required value of the thread tension can be adjusted by the mean of the spring 12 and the nut 14 . During the rectangular pulse duration the actuating pulse generator gives sharp pulses, which triggers the triac VD1. This triac connects the motor to the ac source. And to the motor is applied the voltage, which diagram is shown in Fig. 5e.

\section{CONCLUSION}

In order to get high-quality products in winding fine strip materials it is important to keep the winding-up material with a constant tension force and to damp the oscillations occurring specially in transients. Solving this problem is achieved by using a special transducer with a damper.

The suggested transducer has a piston damper, stoppers, lever and other simple and well-known components. This transducer avoids the disadvantages of the conventional transducer. It gives good regulation for the tension force of the winding-up material (thread, tape, etc.) in the winding electric drives, used in many applications such as in textile industry. The suggested transducer allows the winding-up drive systems to operate without dynamic tension forces and so without oscillations, which cause detriments to the winding material and make its quality worse.

\section{REFERENCES}

1. Abdullah Al-Odienat, 2000. Mathematical modeling of synchronous motor dynamic modes under stochastic processes. $14^{\text {th }}$ European simulation multiconference, Belgium, SCS, ESM, pp: 191-196.

2. Lukhachov, V.L., 2002. Induction electric motors. Colon-p, Moscow, pp: 304.

3. Lalalou, R., T. Bahi and Ne. Debbache, 2001. Fuzzy logic application for an indirect vectorcontrolled induction motor drive. $4^{\text {th }}$ Jordanian International Electrical and Electronics Engineering Conference Proceedings, JEA, IEE, IEEE, Jordan, pp: 241-247.

4. Sen, P.C., 1997. Principles of Electric Machines and Power Electronics. $2^{\text {nd }}$ Edn., John Wiley and Sons.

5. Jawad Faiz and Mohammad B.B. Sharifian, 2001. Optimal design of three phase induction motors and their comparison with a typical industrial motor. Elsevier Science Ltd. Computer and Elect. Eng., 27: 133-144.

6. Mahddavian, H., A. Zayegh and A. Kalam, 2001. Sizing of a motor for domestic applications. $4^{\text {th }}$ Jordanian International Electrical and Electronics Engineering Conference Proceedings, IEE, IEEE, JIEEC, pp: 237-241.

7. Addasi, E.S., 2000. Universal mathematical model of motor drives. $14^{\text {th }}$ European Simulation Multiconference, Belgium. SCS, ESM, pp: 181186.

8. Addasi, E.S., 1993. Elaboration and investigation into wind-up motion with magnetoelectric drive and microprocessor control. Ph.D. Thesis, Russia.

9. Addasi, E.S., 2004. An electric drive with a special measuring disc. International Engineering Conference Proceedings, Mutah.

10. Ben-Brahim, L., S. Tadakuma and A. Akdag, 1999. Speed control of induction motor without rotational transducers. IEEE Trans. Industry App., 35: 844849.

11. Bose, K. and M.G. Simoes, 1995. Speed sensorless hybrid vector controlled induction motor drive. IEEE/IAS Annu. Meet. Conf. Rec., pp: 137-143.

12. Peng, F.Z. and T. Fukao, 1994. Robust speed identification for speed-sensorless vector control of induction motor. IEEE Trans. Industry App., 30: 1234-1240.

13. Patent USSR, 1988. Number 1447740. Published in Invention Bulletin Number 48.

14. Patent USA, 1986. Number 4566646. Classification MKI B65 H 59/38. 